\title{
Characterization and Biocompatibility of Chitosan Gels with Silver and Gold Nanoparticles
}

\author{
C. Sámano-Valencia, ${ }^{1,2}$ G. A. Martínez-Castañón, ${ }^{1,2}$ F. Martínez-Gutiérrez, ${ }^{3}$ \\ F. Ruiz, ${ }^{1,4}$ J. F. Toro-Vázquez, ${ }^{3}$ J. A. Morales-Rueda, ${ }^{3}$ L. F. Espinosa-Cristóbal, ${ }^{5}$ \\ N. V. Zavala Alonso, ${ }^{2}$ and N. Niño Martínez ${ }^{4}$ \\ ${ }^{1}$ Doctoral Program in Materials Science and Engineering, Autonomous University of San Luis Potosi, Salvador Nava Avenue s/n, \\ Universitary Campus, 78290 San Luis Potosí, SLP, Mexico \\ ${ }^{2}$ Master and Doctoral Program in Advanced Dentistry, Faculty of Dentistry, Autonomous University of San Luis Potosi, \\ Salvador Nava Avenue No. 2, Universitary Campus, 78290 San Luis Potosí, SLP, Mexico \\ ${ }^{3}$ Faculty of Chemistry, Autonomous University of San Luis Potosi, Salvador Nava Avenue No. 6, Universitary Campus, \\ 78290 San Luis Potosí, SLP, Mexico \\ ${ }^{4}$ Faculty of Science, Autonomous University of San Luis Potosi, Salvador Nava Avenue s/n, Universitary Campus, \\ 78290 San Luis Potosí, SLP, Mexico \\ ${ }^{5}$ Faculty of Dentistry, Juarez University of Durango State, Predio Canoas s/n, Los Ángeles, 34000 Durango, DGO, Mexico
}

Correspondence should be addressed to G. A. Martínez-Castañón; mtzcastanon@fciencias.uaslp.mx

Received 12 May 2014; Accepted 19 August 2014; Published 15 September 2014

Academic Editor: Ruibing Wang

Copyright ( 92014 C. Sámano-Valencia et al. This is an open access article distributed under the Creative Commons Attribution License, which permits unrestricted use, distribution, and reproduction in any medium, provided the original work is properly cited.

\begin{abstract}
The presence of bacterial resistance to antibiotics is a very important issue and the search of new alternatives is necessary. In this work, a combination of chitosan gel with silver or gold nanoparticles was prepared and characterized using thermal, rheology, bactericide, and biocompatibility analyses. ESEM images were also taken to visualize the incorporation of the nanoparticles into the gel matrix. Thermal analysis showed a better thermal stability in the chitosan-gold nanoparticles gels compared to the chitosan-silver nanoparticles gels. Rheology analyses showed that the viscosity of the gels decreased when velocity increased and there were differences in viscosity when silver and gold nanoparticles concentrations change. ESEM images showed the presence of agglomerates of silver and gold nanoparticles into the gel matrix with a good distribution; in some cases the formation of microstructures was found. Bactericide results show that these materials present an antibacterial activity against $S$. aureus, $S$. mutans, and E. coli. The biocompatibility test showed neither negative reaction nor wound healing delay after the application of the gels in an in vivo test. The gels with silver and gold nanoparticles could be used to treat wound infections in oral or skin applications.
\end{abstract}

\section{Introduction}

The development of bacterial resistance to antibiotics has become an important health problem; it is common in isolates from healthy persons and from patients with community acquired infections in developing countries. Resistance is increasing, particularly to first line, inexpensive, and broadspectrum antibiotics but also to the new drugs; therefore the search of new alternatives is necessary $[1,2]$. In the specific case of dental caries there are reports of bacterial resistance to the substances used to prevent this disease [3]. Dental caries is one of the most common oral diseases all over the world and Streptococcus mutans is its main etiological agent [4]. The role of Streptococcus mutans in the development of dental caries is well established but the no life threatening nature of dental caries has minimized its importance in human health; however the economic cost for the treatment of this oral disease is high $[5,6]$; that is why the prevention approach and the search of new ways for the treatment of dental caries are very important. 
In recent years, the application of nanoparticles (NPs) in various fields has expanded considerably. NPs have been successfully applied in the medical and pharmaceutical fields for the delivery of therapeutic agents, in chronic disease diagnostics, and in biomedical sensors [7]. Silver nanoparticles (AgNPs) and gold nanoparticles (AuNPs) can be found in a number of commercial products including food packing materials and kitchen appliances and are even sold as an alternative "health supplement" [8]. In addition, AgNPs have been examined for their ability to reduce microbial infections in skin [9] and burn wounds [10] and also to prevent bacterial colonization on various surface devices such as catheters and prostheses [11, 12]; the main applications of AuNPs can be found in the biomedical field as antibacterial, contrast agents, and hyperthermia $[7,13]$.

An important factor to take into consideration when nanoparticles are going to be used is the way they are transported to the site of action; for this, several methods like films, nanocapsules, foams, and gels have been used [14-16]. The combination of metallic nanoparticles and polymers has attracted a lot of attention due to its potential applications [17]. Chitosan is one of the most used polymers; it is obtained by deacetylation of chitin, an abundant polysaccharide found in nature as a component of exoskeletons of crustaceans and insects. Chitosan is reported to be biodegradable, biocompatible, and nontoxic [17] and has been previously used to transport several drugs with good results like sustained release and permanence in the action site due to its mucoadhesive property [17-21]. Chitosan also enhances the healing process by increasing the infiltration of inflammatory cells in the injured area and by stimulating macrophages and fibroblasts [18].

In the current work a chitosan gel was prepared and mixed with silver and gold nanoparticles; different concentrations of the components were used in order to evaluate the changes in the properties of the polymer-nanoparticles combination. These polymer gels were characterized using differential scanning calorimetry (DSC), rheometry test (RT), and environmental scanning electron microscopy (ESEM). The antimicrobial activity of the gels was tested on four types of both gram-positive and gram-negative bacteria, including clinical isolates of Streptococcus mutans. Finally, a biocompatibility test of the gels was performed. Although the final application of the material characterized is beyond this work, the main focus is to provide silver and gold nanoparticles with a vehicle or release system.

\section{Materials and Methods}

2.1. Materials. Chitosan (high molecular weight, 85\% DD, Sigma-Aldrich), auric tetrachloride $\left(\mathrm{HAuCl}_{4}, 99.9 \%\right.$, SigmaAldrich), glycerol $\left(\mathrm{C}_{3} \mathrm{H}_{8} \mathrm{O}_{3}, 99.5 \%\right.$, Sigma-Aldrich), gallic acid $\left(\mathrm{C}_{7} \mathrm{H}_{6} \mathrm{O}_{5}\right.$, Sigma-Aldrich), silver nitrate $\left(\mathrm{AgNO}_{3}, \mathrm{CTR}\right.$ Scientific), acetic acid $\left(\mathrm{C}_{2} \mathrm{H}_{4} \mathrm{O}_{2}, 99.7 \%\right.$, J.T. Baker $)$, and sodium hydroxide $(\mathrm{NaOH}, 98.2 \%$, Baker) were used as received. Brain heart infusion and bactoagar for the microbiological analyses were purchased from BD DIFCO and used without previous treatment.
2.2. Preparation of Nanoparticles Dispersion. Silver nanoparticles: $0.169 \mathrm{~g}$ of silver nitrate was dissolved in $100 \mathrm{~mL}$ of deionized water; then we added $0.1 \mathrm{~g}$ of gallic acid previously dissolved in $10 \mathrm{~mL}$ of deionized water and immediately after the $\mathrm{pH}$ was adjusted to $11 \mathrm{using}$ a $1.0 \mathrm{M} \mathrm{NaOH}$ solution [22].

Gold nanoparticles: $100 \mathrm{~mL}$ of a $0.001 \mathrm{M}$ gold solution was prepared from $\mathrm{HAuCl}_{4}$ and deionized water. To this solution, $10 \mathrm{~mL}$ of deionized water containing $0.001 \mathrm{~mol}$ of gallic acid was added under magnetic stirring and then the $\mathrm{pH}$ was adjusted to 10 using a $0.1 \mathrm{M} \mathrm{NaOH}$ solution [13].

2.3. Characterization of Nanoparticles Dispersion. The silver and gold nanoparticles were characterized, to know particle size, with dynamic light scattering (DLS, Zetasizer Nano ZS, Malvern) operating with a He-Ne laser at a wavelength of $633 \mathrm{~nm}$ and a detection angle of $90^{\circ}$; all samples were analyzed for $60 \mathrm{~s}$ at $25^{\circ} \mathrm{C}$ and, to know morphology, with transmission electron microscopy (TEM, JEOL JEM-1230) at an accelerating voltage of $100 \mathrm{kV}$.

2.4. Preparation of the Gels. Chitosan gels with a concentration of 2,4 , and 6 vol\% of acetic acid were prepared with the following procedure: $1.75 \mathrm{~g}$ of chitosan and $0.2 \mathrm{~mL}$ of glycerol were added to $49.8 \mathrm{~mL}$ of a 2, 4, or 6 vol\% acetic acid solution in deionized water. This mixture was stirred at $1000 \mathrm{rpm}$ at room temperature during 5 minutes until the gel was formed.

Chitosan Gel with AgNPs. $2 \mathrm{~mL}$ of acetic acid was added to $47.8 \mathrm{~mL}$ of a dispersion of AgNPs at different concentrations $(0.1 \mathrm{wt} \%, 0.05 \mathrm{wt} \%$, and $0.025 \mathrm{wt} \%)$. To the mixture with $0.1 \mathrm{wt} \%$ of AgNPs, different amounts of chitosan were added (3.5 wt $\%, 1.75 \mathrm{wt} \%$, and $0.875 \mathrm{wt} \%$ ) and $0.2 \mathrm{~mL}$ of glycerol was also added. The mixture was stirred under the same conditions as mentioned until the gel was formed.

Chitosan Gel with AuNPs. The same procedure as in the chitosan gel with AgNPs; the difference was the AuNPs solution concentrations ( $0.02 \mathrm{wt} \%, 0.01 \mathrm{wt} \%$, and $0.005 \mathrm{wt} \%$, resp.). A total of 13 different gels were prepared; see Table 1 for more details.

2.5. Characterization of the Gels. The gels were characterized using differential scanning calorimetry (DSC), rheometry test (RT), and environmental scanning electron microscopy (ESEM). A DSC calorimeter (Waters DSC 500) was used with a constant heating rate of $20^{\circ} \mathrm{C} / \mathrm{min}$ from room temperature to $1000^{\circ} \mathrm{C}$ under nitrogen atmosphere. The rheometry test was performed with a U.S. 200, Paar Physica Rheometer equipped with a Peltier temperature control. The determination was carried using a cone-plate geometry (MK31, $50 \mathrm{~mm}$ in diameter, $1^{\circ}$ tilt, and 0.49 -micron truncation). An aliquot of the sample was deposited at the base of the plate to further secure the upper cone. Determining viscosity was carried out at a temperature of $25^{\circ} \mathrm{C}$; the shear rate increased from $50 \mathrm{rpm}$ to $250 \mathrm{rpm}$. The distribution of the nanoparticles in the gels was observed using an environmental scanning electron microscope (ESEM Quanta 200, FEI) and no special preparation of the sample was needed for this observation. 
TABLE 1: Concentrations of the different reagents used to prepare the gels.

\begin{tabular}{lcccc}
\hline Sample & \%wt Ag & \%wt chitosan & \%vol acetic acid & \%wt Au \\
\hline Ag1Ch3.5 & 0.1 & 3.5 & 4 & - \\
Ag05Ch3.5 & 0.05 & 3.5 & 4 & - \\
Ag02Ch3.5 & 0.025 & 3.5 & 4 & - \\
Ag1Ch1.7 & 0.1 & 1.75 & 4 & - \\
Ag1Ch.875 & 0.1 & 0.875 & 4 & - \\
Au02Ch3.5 & - & 3.5 & 4 & 0.02 \\
Au01Ch3.5 & - & 3.5 & 4 & 0.01 \\
Au005Ch3.5 & - & 3.5 & 4 & 0.005 \\
Au02Ch1.7 & - & 1.75 & 4 & 0.02 \\
Au02Ch.875 & - & 0.875 & 4 & 0.02 \\
Ch2 & - & 3.5 & 2 & - \\
Ch4 & - & 3.5 & 4 & - \\
Ch6 & - & 3.5 & 6 & - \\
\hline
\end{tabular}

2.6. Antimicrobial Test. The following gram-negative microorganism was evaluated: Escherichia coli (ATCC 25922). Two variants of gram-positive microorganisms were tested: reference strains of Streptococcus mutans carious dentine (ATCC 25175) and (ATCC 81146), Staphylococcus aureus (ATCC 29213), and four clinical isolates of Streptococcus mutans.

For the antimicrobial assays the bacterial strains were grown overnight in $\mathrm{BHI}$ broth at $37^{\circ} \mathrm{C}$. The bacterial concentration was standardized to an optical density of 0.08 at $600 \mathrm{~nm}$ (approximately $1.5 \times 10^{8} \mathrm{UFC} / \mathrm{mL}$ ) using the McFarland scale.

For the well diffusion assay BHI solid media were prepared and sterilized at $121^{\circ} \mathrm{C}$ for $20 \mathrm{~min}$. Approximately $20 \mathrm{~mL}$ of the sterilized media was poured in petri dishes $(100 \times$ $20 \mathrm{~mm}$ ) in an aseptic environment. The diffusion test was performed according to previous reports [23] with a few modifications. Wells of $6 \mathrm{~mm}$ were made in the agarized medium after inoculation with the bacterial strains. The wells were filled with $1000 \mu \mathrm{L}$ of the gels samples. On each plate the gels were tested as follows: three plates for the 3 chitosan gels, three plates for the 5 chitosan gels with AuNP gels, and three plates for the 3 chitosan gels, three plates for the 5 chitosan gels with AuNP, and three plates for the 5 chitosan gels with AgNP. The plates were incubated at $37^{\circ} \mathrm{C}$ for $24 \mathrm{~h}$ before visual assessment of the inhibition zones. The experiment was repeated three times. The quantification of microbial growth inhibition was determined by measuring the diameter of clear zones of microbial growth around the wells in the agar; that inhibition was measured using a digital vernier caliper.

2.7. In Vivo Test. The materials chosen for this test were those with the highest content of silver or gold nanoparticles because it is well known that, for a given material, at the highest concentration, the material could have the most toxic effect. The protocol for this study was conducted under the test guidelines of the Organization for Economic Cooperation and Development (OECD 1995) applying good laboratory practices (GLP) and approved by the investigation committee of the master's degree in advanced clinical dentistry. 15 healthy Wistar rats $(230 \mathrm{~g})$ were divided into three groups $(n=5)$. Each group was treated with a different gel, (a) chitosan gel with AgNPs (Ag1Ch3.5), (b) chitosan gel with AuNPs (Au02Ch3.5), and (c) chitosan gel without nanoparticles (Ch4). The animals were kept in individual cages with water and food (rodent chow) ad libitum.

For the experiment, each rat was anesthetized with an intraperitoneal injection of ketamine $(8-12 \mathrm{mg} / \mathrm{Kg})$ and xylazine $(30-50 \mathrm{mg} / \mathrm{Kg}$ ) and shaved in the dorsum area to perform a $1 \mathrm{~cm}$ incision. In each incision $200 \mu \mathrm{L}$ of gels was spread after UV sterilization. The incision was closed using a 3-0 silk. The rats were observed after 28 days; the main points of observation were behavior and response of the tissue to the gel.

2.7.1. Histological Analysis. After the wound was epithelialized (28 days) a full-thickness biopsy was taken. The samples were stored in $10 \%$ formaldehyde for $48 \mathrm{~h}$ prior to inclusion in paraffin. After that, each histological sample was stained using hematoxylin-eosin and Masson's trichrome staining methods. The qualitative analysis was done with a light microscope (Olympus, 100X magnification).

2.8. Statistical Analysis. For the bactericide evaluation, all of the experimental results are expressed as mean \pm standard deviation (SD) of three determinations. Student $t$-test was used for statistical analysis and a $P$ value $<0.05$ was considered significant.

\section{Results and Discussion}

3.1. Characterization of the Gels. In general terms the hydrogels present several characteristics like high water vapor and oxygen permeability, as well as mechanical properties that resemble physiological soft tissues [9]. Those characteristics make hydrogels eligible for several possible applications as in this case, where chitosan gels are intended to be used to transport silver or gold nanoparticles.

AgNP and AuNP were synthetized according to methods previously published $[13,22]$. From DLS analysis, AgNP size was $7 \pm 1.1 \mathrm{~nm}$ (inset Figure 1(a)) and AuNP size was $13 \pm$ $0.7 \mathrm{~nm}$ (inset Figure 1(b)), both with spherical shape (Figures $1(\mathrm{a})$ and $1(\mathrm{~b}))$. The gels prepared with different concentrations of the components are shown in Figure 2. Qualitatively, the Ag gels had a brown color with slight differences in the tone depending on the amount of Ag used in the solution. The Au gels presented a dark brown color with no apparent difference in the tone when the Au nanoparticles solution decreased. The gels without nanoparticles presented an amber color. The color was related to the nanoparticles solution used. The appearance is important due to a possible future application where the gel could be applied in infected sites.

3.2. DSC Analysis. TGA analyses for chitosan gel without nanoparticles and chitosan gel with AgNPs have been previously reported [23]. However, the thermal analysis of the composite made with the addition of silver and gold 


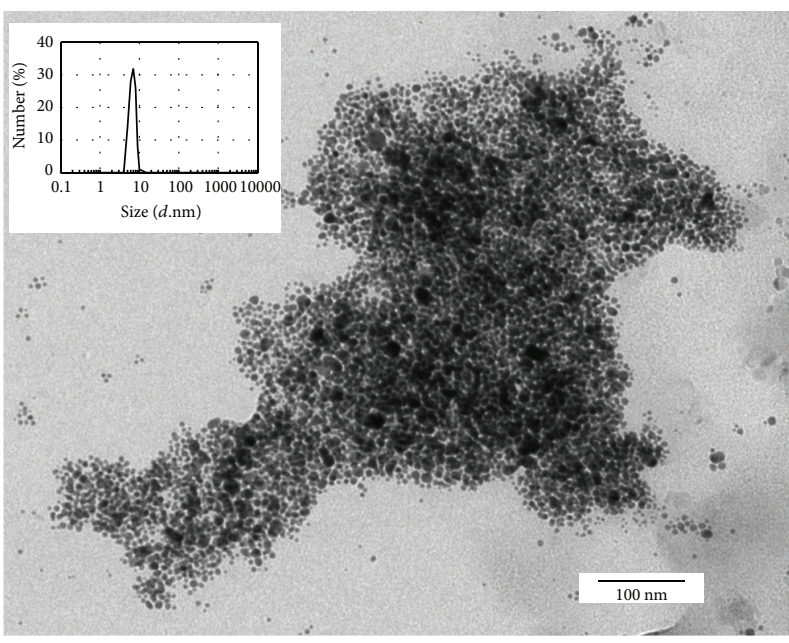

(a)

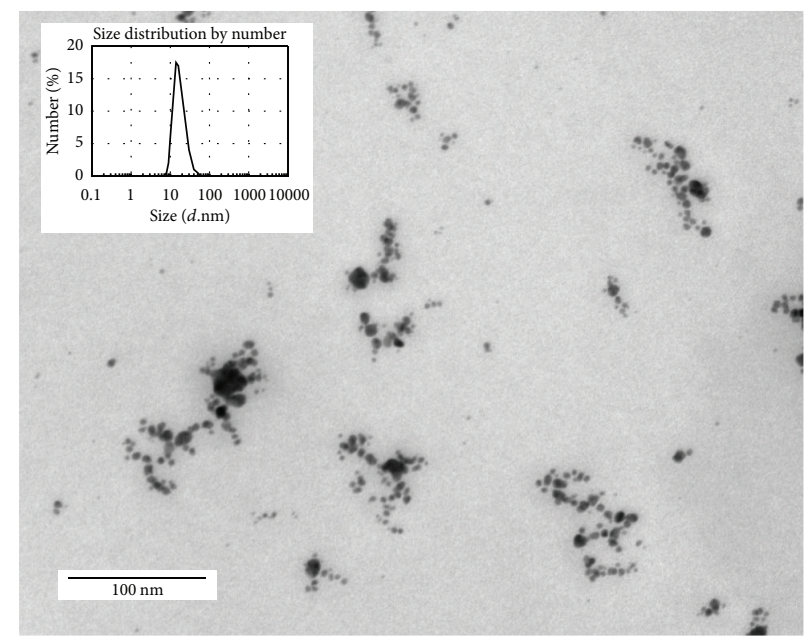

(b)

Figure 1: (a) Ag nanoparticles and (b) Au nanoparticles.

TABLE 2: TGA and DSC results of all the synthesized gels.

\begin{tabular}{|c|c|c|c|c|}
\hline Label & Exothermic peak $\left({ }^{\circ} \mathrm{C}\right)$ & First weight loss $(\%)^{*}$ & Second weight loss $(\%)^{* *}$ & Residues $(\%)^{\dagger}$ \\
\hline Ag1Ch3.5 & 116.88 & $93.01(40-200)$ & 4.55 & 0.475 \\
\hline Ag05Ch3.5 & 125.94 & $89.19(50-175)$ & 8.71 & 1.504 \\
\hline Ag02Ch3.5 & 112.50 & $93.37(30-147)$ & 2.948 & 1.569 \\
\hline Ag1Ch1.7 & 123.50 & $95.50(30-200)$ & 1.386 & 2.338 \\
\hline Ag1Ch.875 & 122.40 & $96.88(30-200)$ & 1.511 & 0.55 \\
\hline $\mathrm{Au} 02 \mathrm{Ch} 3.5$ & 144.81 & $78.20(30-200)$ & 12.06 & 7.82 \\
\hline Au01Ch3.5 & 133.63 & $86.34(30-200)$ & 6.54 & 5.904 \\
\hline $\mathrm{Au} 005 \mathrm{Ch} 3.5$ & 112.50 & $93(30-200)$ & 4.90 & 0.542 \\
\hline Au02Ch1.7 & 123.23 & $95.50(30-200)$ & 1.38 & 0.77 \\
\hline $\mathrm{Au} 02 \mathrm{Ch} .875$ & 132.57 & $91.85(30-200)$ & 5.52 & 0.569 \\
\hline Ch2 & 136.92 & $63.38(30-200)$ & 26.25 & 8.07 \\
\hline Ch4 & 109 & $81.26(30-200)$ & 2.27 & 15.46 \\
\hline Ch6 & 112.23 & $89.50(30-200)$ & 6.279 & 1.91 \\
\hline Ch-gallic acid & 103.18 & $93.39(20-200)$ & 2.76 & 0.92 \\
\hline
\end{tabular}

${ }^{*}$ The temperature range at which this loss occurred is indicated for each sample; ${ }^{* *}$ the temperature range considered for this loss is $200-575^{\circ} \mathrm{C}$; ${ }^{\dagger}$ these values were obtained at $950^{\circ} \mathrm{C}$.

nanoparticles at different concentrations into a chitosan gel has not been explored before this study. Figure 3 shows two representative curves of these thermal analyses and TGA and DSC results for all the gels are shown in Table 2; in general, the gels showed two weight losses, the first weight loss corresponds to water loss, and the second loss corresponds to decomposition of chitosan [24-26] which starts by a random split of the glycosidic bonds, followed by a further decomposition forming acetic and butyric acids and a series of lower fatty acids, where C2, C3, and C6 predominate [27].

As we can see from Table 2, the amount of weight loss is different from sample to sample ranging from 63.38 to $96.88 \%$ and, for the first weight loss, the temperature range at which is achieved also changes for each sample. These differences could be related to the different interactions between metallic nanoparticles and chitosan chains through its amine and hydroxyl groups. Neto et al. reported that the water content in a chitosan gel is affected by the number of ionic groups in the material as well as their nature; the important binding sites for water molecules in chitosan are the hydroxyl and amine groups present in its chain; for our samples we propose that these ionic sites are partially occupied by nanoparticles and the amount of water molecules bonded to the chitosan chains changes with the amount of nanoparticles; this could be the reason why gels without nanoparticles present a low water loss and samples with high amount of nanoparticles present a high water loss [27].

According to our results, the addition of $\mathrm{Ag}$ and $\mathrm{Au}$ nanoparticles to a chitosan gel produces a higher thermal stability compared to gels without nanoparticles (it is reflected on the temperature of the endothermic peak); for example, sample Ch4 has an endothermic peak at $109^{\circ} \mathrm{C}$ and sample 


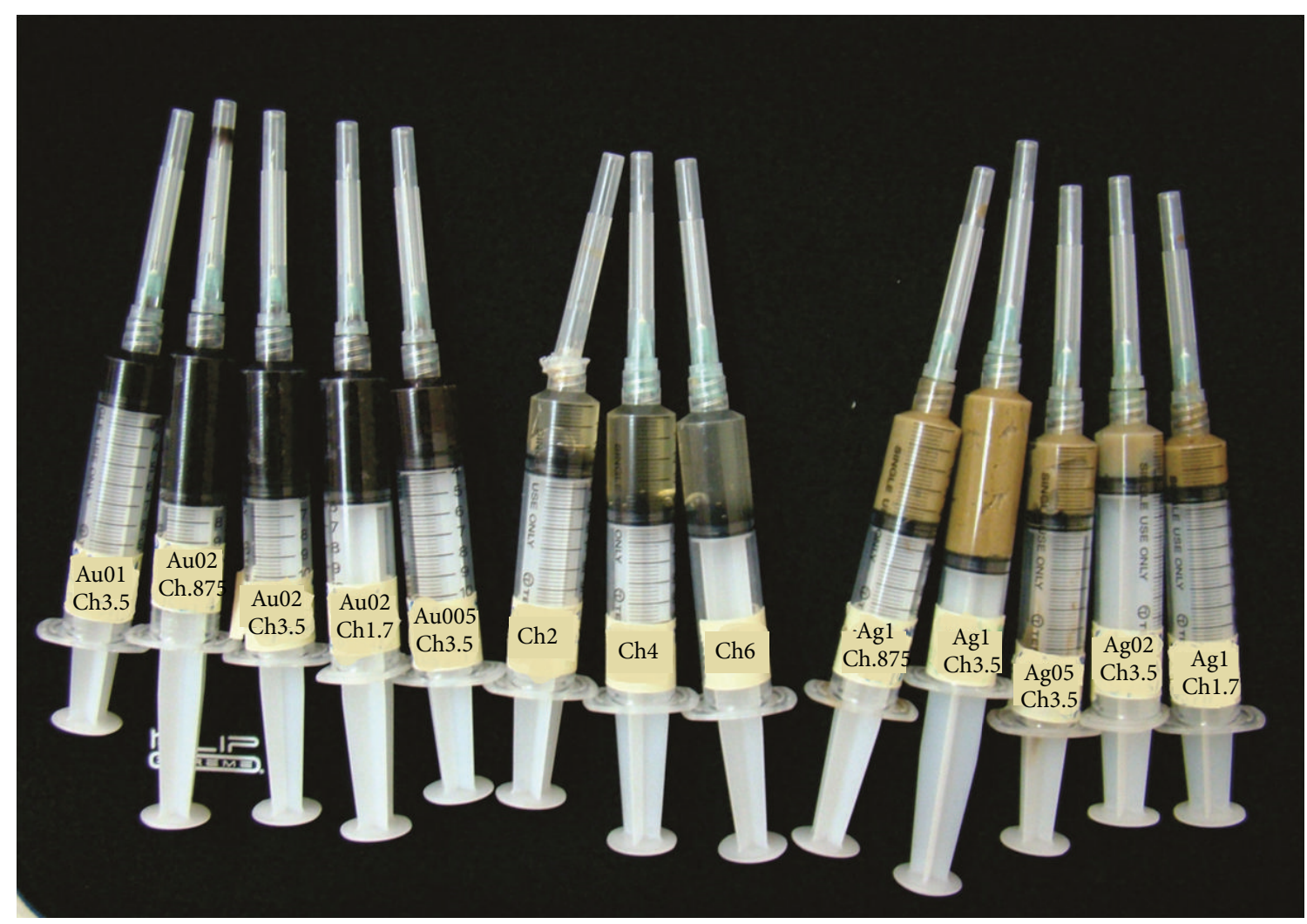

(a)

(b)

(c)

Figure 2: (a) Au gels, (b) chitosan gels, and (c) Ag gels. Gels are presented in syringes just for this image; it does not correspond to a specific intended application.

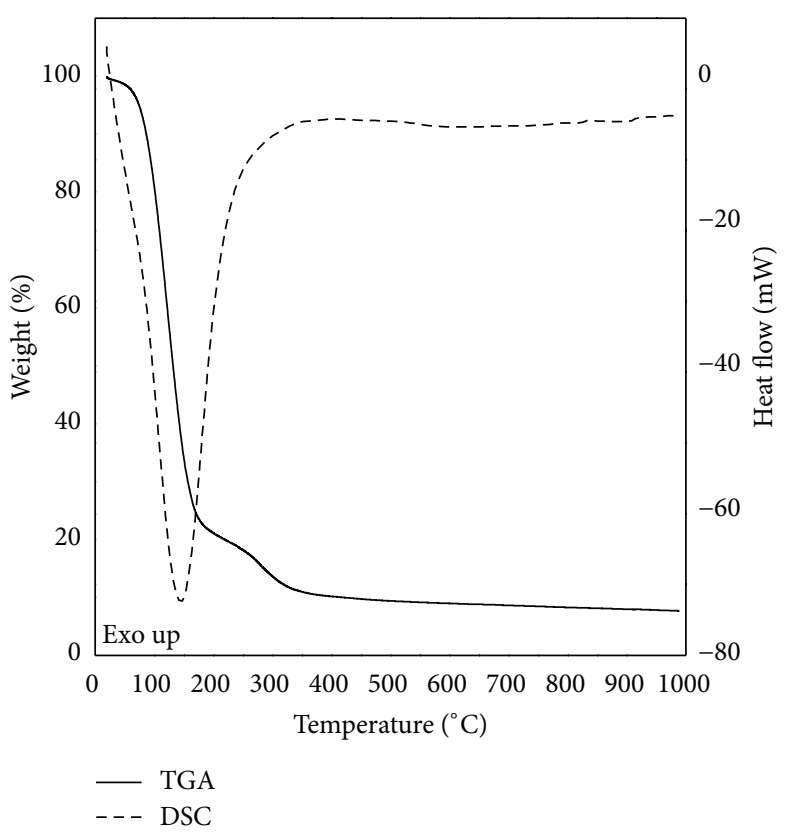

(a)

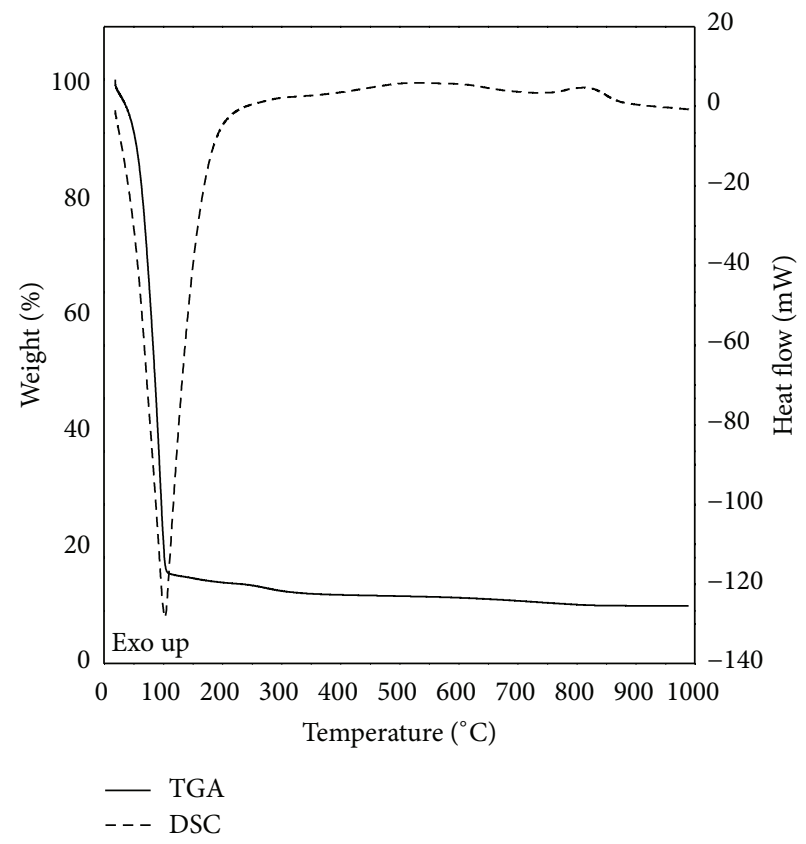

(b)

Figure 3: TGA and DSC analysis of selected samples. (a) Au02Ch3.5 and (b) Ch-gallic acid gel. 


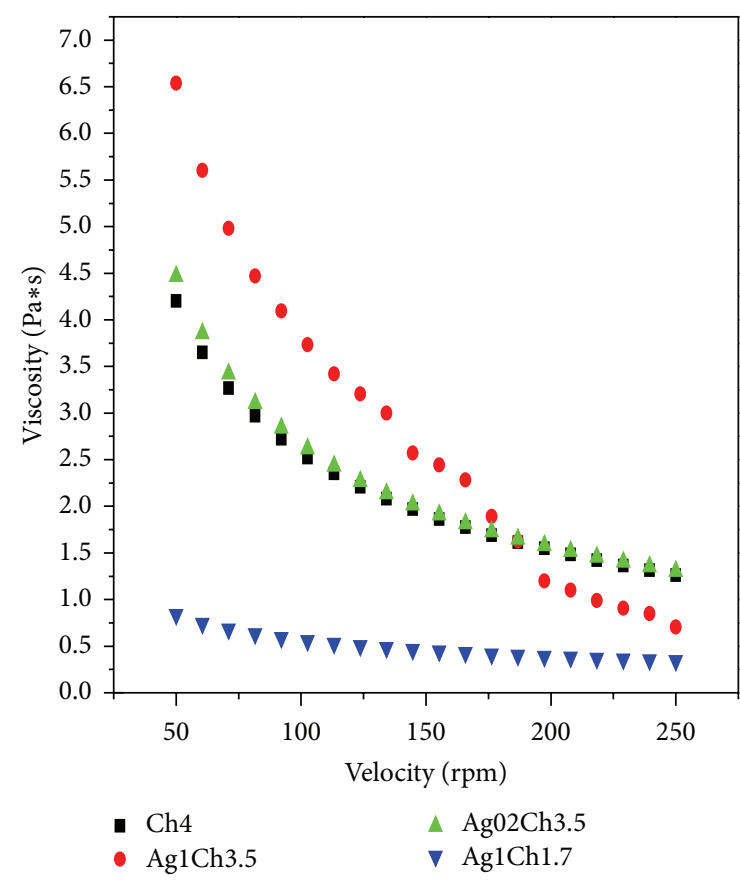

(a)

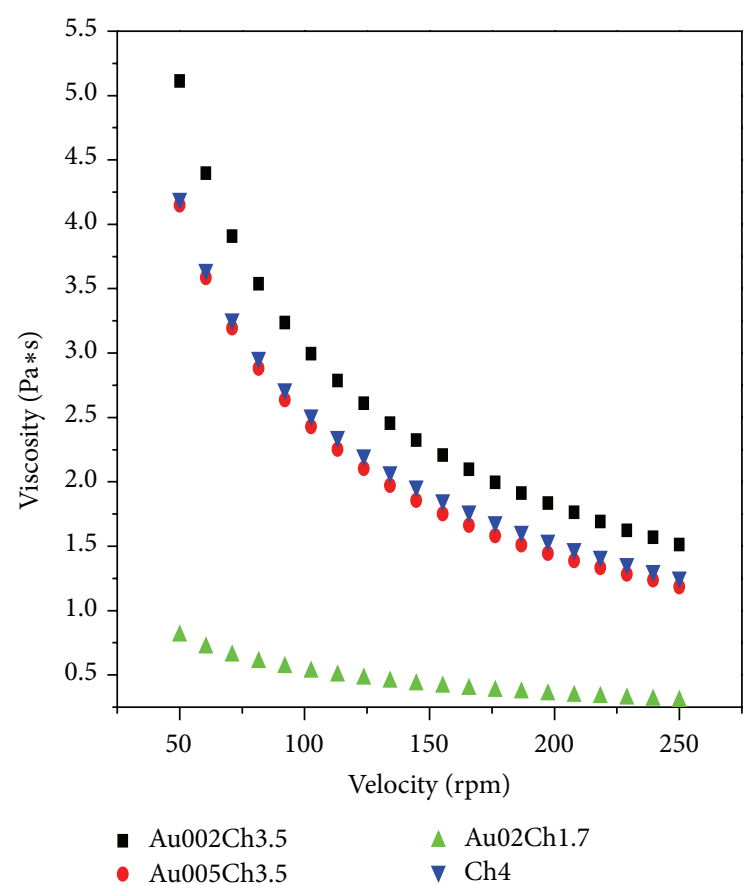

(b)

FIGURE 4: Viscosity test of the gels with a 4 vol\% of acetic acid and with (a) AgNPs and (b) AuNPs.

Au02Ch3.5 (the sample with the highest Au content) has an endothermic peak at $144.81^{\circ} \mathrm{C}$; these results agree with a previous report where a chitosan gel with iron oxide nanoparticles was prepared [24].

3.3. Viscosity Test. Gels consistency is a very important feature for the manipulation of the product and is related to its viscosity. Part of our work was focused on finding the gel with the best manipulation characteristics without affecting its bactericide properties. We observed a change in the viscosity values when the chitosan quantity decreased making the gels less viscous in all cases. The viscosity test was performed to evaluate the change in properties of the synthesized gels depending on the concentration of the components. Due to the low viscosity of gels without nanoparticles, they were not analyzed and high and low concentrations of the metal nanoparticles and chitosan were evaluated and results are shown in Figure 4; in general terms, the viscosity decreases when the chitosan concentration decreases while the Ag and $\mathrm{Au}$ concentrations remain the same. The highest viscosity values were obtained in the gels containing $0.02 \%$ and $0.1 \%$ of $\mathrm{Au}$ and $\mathrm{Ag}$ nanoparticles, respectively; this could be produced as a consequence of the electrostatic interactions between the chitosan and the metal nanoparticles but seems to be more dependent on the chitosan concentration. When the chitosan concentration decreases the viscosity does too, presumably, because of a lack of interaction between the amino groups with the metal nanoparticles. The gels showed a pseudoplasticity or shear thinning behavior, a desirable property that could be used when the gels would be applied.
This can be advantageous, since the gel would become more fluid while it is manipulated leading to an easier application. In addition, the viscosity would probably increase when the stress ceased, avoiding the gel to flow from the site of application [18].

Nascimento et al. prepared a chitosan gel with silver sulfadiazine and reported that the presence of silver sulfadiazine increased the viscosity of the material and an increase of the shear rate decreases the viscosity; although the silver compound is different to ours the results are similar, confirming that viscosity is strongly dependent on the chitosan concentration [18].

3.4. ESEM Characterization. Once inside the chitosan matrix, nanoparticles agglomerate but the ESEM images (Figures 5 and 6) show a good distribution of these agglomerates into the gel matrix and when the concentrations of silver nanoparticles and chitosan decreased the formation of different microparticles was observed with morphologies like cubes and dendrites (Figures 5(b), 5(c), and 5(e)); this could be done to attraction forces between the nanoparticles inside the gel matrix that makes them move, agglomerate, and form the crystal structures. Twu et al. prepared silver nanoparticles using chitosan suspensions and under certain conditions, they observed the formation of microstructures with triangleshaped morphology; they explained that in some cases, water molecules with chain-like hydrogen-bonded could be close together thereby forming templates that assist the initial growth of $\mathrm{Ag}$ nanoparticle which finally leads to the formation of these special structures [28]. In our study, gels 


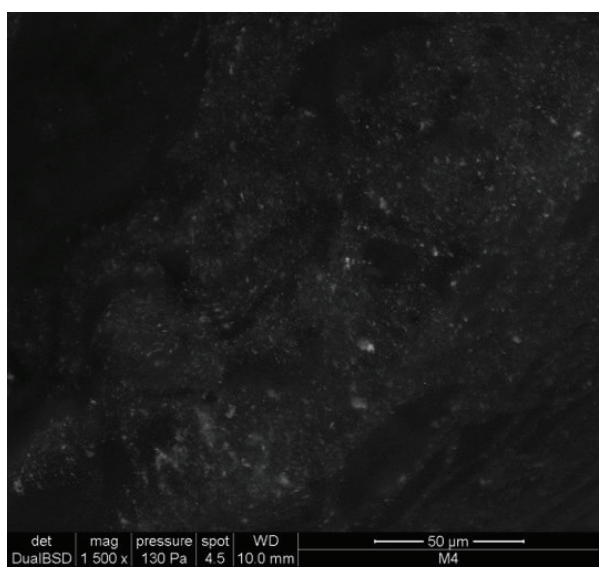

(a)

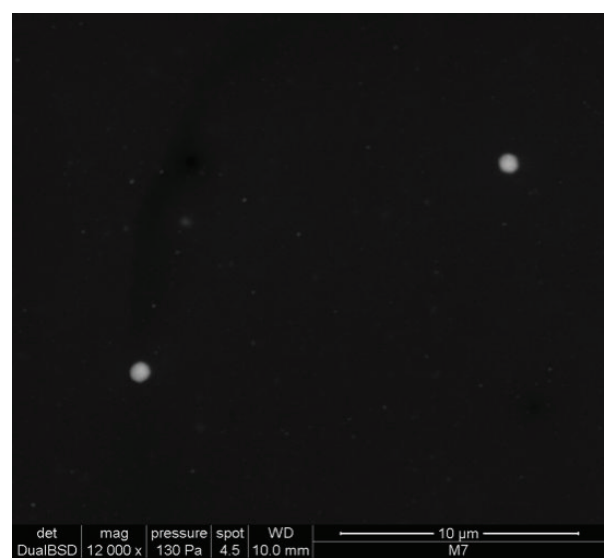

(c)

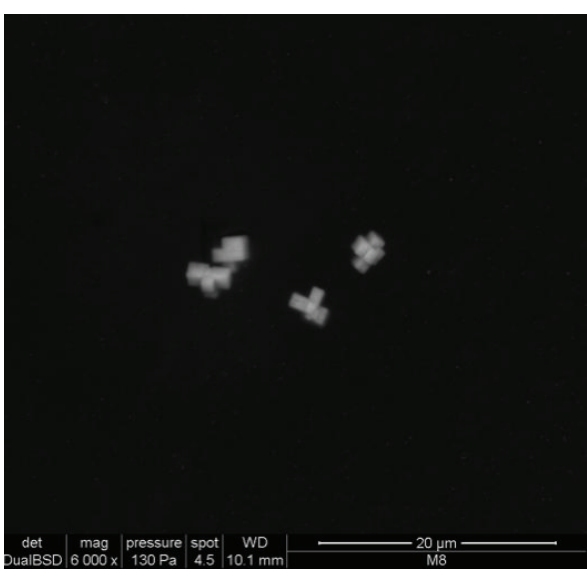

(b)

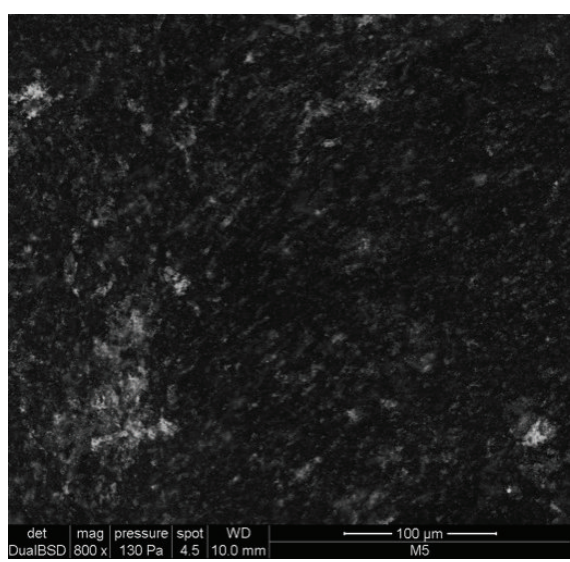

(d)

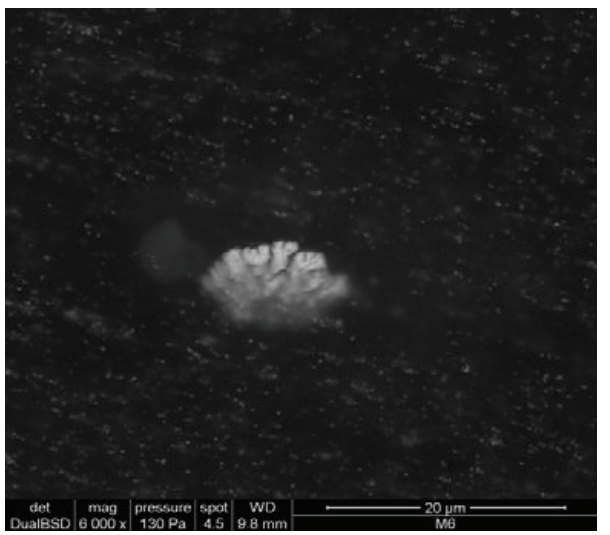

(e)

Figure 5: ESEM images of chitosan gels with AgNPs. (a) Ag1Ch3.5; (b) Ag05Ch3.5; (c) Ag02Ch3.5; (d) Ag1Ch1.7; and (e) Ag1Ch.875.

with gold nanoparticles did not show the same phenomena maybe due to the lower gold concentration (Figure 6).

This behavior could be a good characteristic because it seems that nanoparticles are not strongly linked to the gel matrix and can migrate from the gel to the action site. Hsu et al. [29] reported a different behavior of a composite made of silver or gold nanoparticles and chitosan; that is, nanoparticles present an agglomeration only at higher concentrations; this difference could be due to the origin of the nanoparticles. Hsu et al. obtained the nanoparticles from a physical method, and our nanoparticles come from a chemical method [30].

3.5. Antimicrobial Test. Metal nanoparticles have shown important antibacterial activity likely due to both their size and high surface to volume ratio; those characteristics allow 


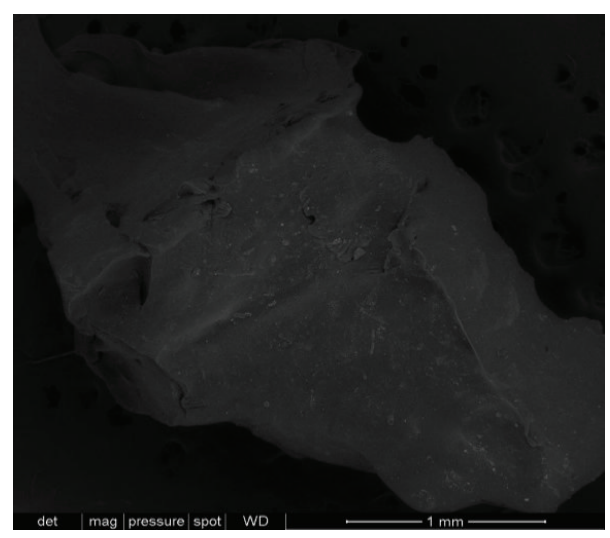

(a)

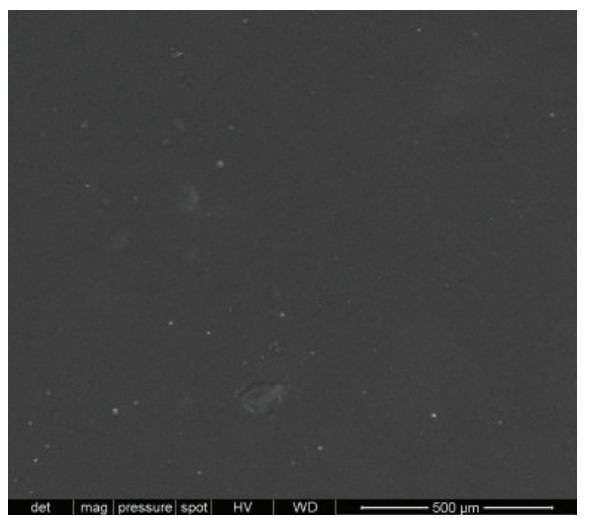

(c)

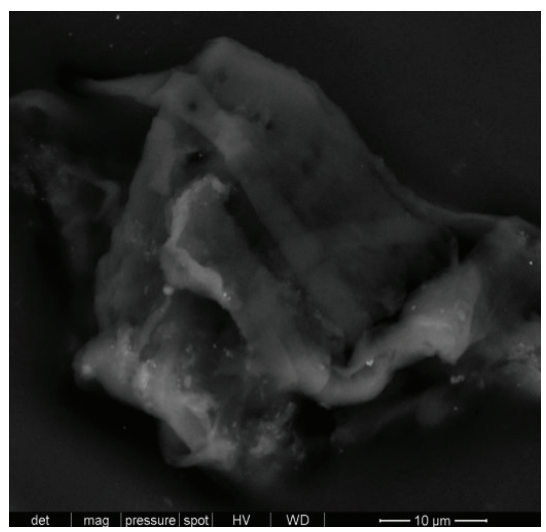

(b)

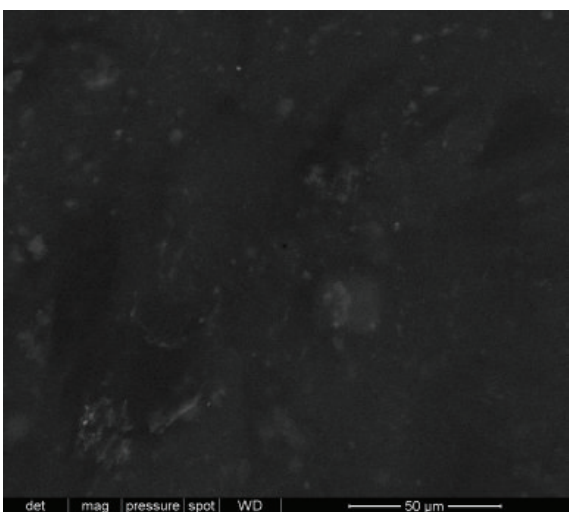

(d)

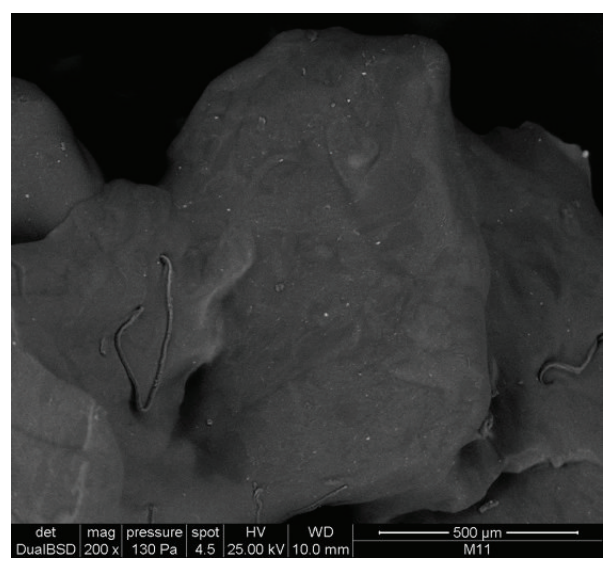

(e)

Figure 6: ESEM images of chitosan gels with AuNPs. (a) Au02Ch3.5; (b) Au01Ch3.5; (c) Au005Ch3.5; (d) Au02Ch1.75; and (e) Au02Ch.875.

them to interact with bacterial membranes producing the biocide effect by a combination of mechanisms. Bacterial walls are different depending on the thickness of their peptidoglycan layer; this characteristic classifies bacteria into gram-negative and gram-positive groups [2, 4]. Silver and gold nanoparticles have been tested on different bacteria both gram-negative and gram-positive with inhibitory effects $[2,4,13]$.

The antibacterial activity of the gels was tested using $\mathrm{BHI}$ agar plates inoculated with different bacteria; this is a common method already reported elsewhere [15, 16, 20]; these results are shown in Table 3 . Chitosan gels without nanoparticles presented an inhibition halo from 0 to $21 \mathrm{~mm}$ depending on the bacterium tested and the acetic acid concentration. Because chitosan is only soluble in acidic media, acetic acid was used to dissolve chitosan and thus obtain the gel. When the acetic acid concentration increased, the inhibition zones increased (Table 3); for this reason the $4 \%$ concentration of acetic acid was chosen to prepare samples with nanoparticles in order to not affect either 
TABLE 3: Average (in mm) of the different inhibition zones obtained by the gels tested in each bacterium.

\begin{tabular}{|c|c|c|c|c|c|c|c|c|}
\hline \multirow{2}{*}{ Label } & \multicolumn{4}{|c|}{ Reference strains } & \multicolumn{4}{|c|}{ Clinical isolates } \\
\hline & $\begin{array}{c}\text { S. mutans } \\
\text { ATCC } 25175\end{array}$ & $\begin{array}{c}\text { S. mutans } \\
\text { ATCC } 81146\end{array}$ & $\begin{array}{c}\text { S. aureus } \\
\text { ATCC } 29213\end{array}$ & $\begin{array}{c}\text { E. coli ATCC } \\
25922 \\
\end{array}$ & $\begin{array}{c}\text { S. mutans } \\
54: 2\end{array}$ & $\begin{array}{l}\text { S. mutans } \\
71: 15\end{array}$ & $\begin{array}{c}\text { S. mutans } \\
58: 3\end{array}$ & $\begin{array}{c}\text { S. mutans } \\
51: 2\end{array}$ \\
\hline Ag1Ch3.5 & $16.81 \pm 0.2$ & $10.58 \pm 9.31$ & $17.45 \pm 1.71$ & $14.67 \pm 0.14$ & $8.68 \pm 0.65$ & $10.39 \pm 3.2$ & $8.51 \pm 0.3$ & $9.29 \pm 3.46$ \\
\hline Ag05Ch3.5 & $15.16 \pm 1.60$ & $14.68 \pm 1.16$ & $19.31 \pm 0.60$ & $14.32 \pm 1.09$ & $5.89 \pm 5.22$ & $5.15 \pm 4.46$ & $9.04 \pm 3.1$ & $9.38 \pm 4.33$ \\
\hline Ag02Ch3.5 & $14.36 \pm 0.62$ & $12.29 \pm 4.52$ & $16.76 \pm 3.20$ & $14.75 \pm 0.12$ & $8.68 \pm 2.4$ & $5.05 \pm 4.37$ & $5.35 \pm 4.64$ & $5.68 \pm 9.84$ \\
\hline Ag1Ch1.7 & $16.65 \pm 0.98$ & $15.58 \pm 1.64$ & $19.23 \pm 3.45$ & $15.41 \pm 0.12$ & $9.24 \pm 2.85$ & $11.88 \pm 3.1$ & $9.68 \pm 3.58$ & $11.55 \pm 4.28$ \\
\hline Ag1Ch.875 & $16.87 \pm 2.71$ & $18.17 \pm 1.55$ & $17.32 \pm 1.44$ & $15.84 \pm 0.40$ & $9.63 \pm 2.4$ & $11.16 \pm 5.7$ & $10.2 \pm 3.5$ & $13.08 \pm 4.57$ \\
\hline $\mathrm{Au} 02 \mathrm{Ch} 3.5$ & $17.03 \pm 2.39$ & $12.38 \pm 4.36$ & $17.4 \pm 0.76$ & $14.23 \pm 0.57$ & $9.15 \pm 2.52$ & $8.56 \pm 0.77$ & $7.99 \pm 0.57$ & $9.57 \pm 0.9$ \\
\hline Au01Ch3.5 & $14.43 \pm 0.50$ & $9.12 \pm 7.91$ & $17.91 \pm 2.3$ & $13.17 \pm 0.35$ & $7.07 \pm 6.31$ & $6.06 \pm 5.27$ & $7.93 \pm 0.58$ & $11.67 \pm 3.87$ \\
\hline Au005Ch3.5 & $15.49 \pm 0.28$ & $11.95 \pm 4.45$ & $16.23 \pm 0.58$ & $14.44 \pm 0.43$ & $4.04 \pm 6.99$ & $2.67 \pm 4.62$ & $7.88 \pm 0.5$ & $6.79 \pm 6.29$ \\
\hline Au02Ch1.7 & $15.16 \pm 0.48$ & $15.34 \pm 3.43$ & $17.88 \pm 0.87$ & $15.05 \pm 0.10$ & $11.08 \pm 3.2$ & $9.54 \pm 1.58$ & $7.58 \pm 0.21$ & $11.94 \pm 0.59$ \\
\hline Au02Ch.875 & $15.96 \pm 0.74$ & $14.62 \pm 4.13$ & $17.48 \pm 0.80$ & $16.29 \pm 0.84$ & $10.54 \pm 2.6$ & $10.03 \pm 0.1$ & $7.63 \pm 0.48$ & $10.72 \pm 0.66$ \\
\hline Ch2 & $9.97 \pm 1.02$ & 0 & $11.73 \pm 1.49$ & $9.09 \pm 1.22$ & 0 & 0 & 0 & 0 \\
\hline Ch4 & $8.41 \pm 1.24$ & 0 & $12.06 \pm 1$ & $11.02 \pm 0.18$ & 0 & 0 & 0 & 0 \\
\hline Ch6 & $19.06 \pm 1.63$ & $18.37 \pm 0.33$ & $21.1 \pm 2.55$ & $17.1 \pm 0.93$ & $6.95 \pm 6.02$ & $13.59 \pm 1.4$ & $11.4 \pm 2.08$ & $14.07 \pm 1.65$ \\
\hline
\end{tabular}

the nanoparticles bactericide effect or the solubility of chitosan. It is well known that chitosan by itself presents antibacterial activity when used in large amounts; the proposed mechanism is by binding to the negatively charged bacterial cell wall, with consequent destabilization of the cell envelope and altered permeability, followed by attachment to DNA with inhibition of its replication [8]. Sample Ch4 showed bactericide effect only against standard strains; clinical strains of $S$. mutans were not affected by this sample.

Metal nanoparticles like gold and silver have been explored for their broad-spectrum antimicrobial activity [30]. According to previous studies the inhibition is related to the particle size; the smaller the particle size the better the antibacterial activity $[5,22]$. The proposed mode of action of AgNPs and AuNPs is that they attach to the bacterial cell wall via thiol-containing proteins; they may also compromise cell permeability [16].

Samples with $\mathrm{Ag}$ and $\mathrm{Au}$ nanoparticles showed a bactericide effect against both standard and clinical strains: the sample with the highest inhibition halo was Ag05Ch3.5 against $S$. aureus. It was expected that when the concentration of $\mathrm{Ag}$ and $\mathrm{Au}$ decreased the inhibition zone decreased too; however only slight changes were observed with statistically significant difference with respect to the control, which was sample Ch4. The previous result shows that even when the Ag and $\mathrm{Au}$ concentrations were reduced the antimicrobial effect was very similar so a smaller amount of nanoparticles is still very effective.

Other aspects to take into consideration are the difference between bacteria given the change in membrane structure and the difference between clinical isolate and reference strains [1]. The clinical isolates are more resistant bacterium and this is reflected in smaller inhibition zones. For the reference strains, the statistical analysis applied showed that when compared to the control (Ch4), almost all the gels showed a bigger halo with a statistically significant difference with very similar results between AgNPs and AuNPs gels even though AuNPs concentrations were smaller than AgNPs concentrations. The bacterium with the smaller inhibition zones was $S$. mutans, a result that was expected due to the mayor complexity and resistance of its membrane [5].

3.6. In Vivo Test. In the biocompatibility in vivo test, three groups of rats were tested using the following gels: Ag1Ch3.5, Au02Ch3.5, and Ch4; these gels were chosen because they contained the highest nanoparticle concentrations. The chitosan gel without nanoparticles was used as control, because it has been reported as biocompatible [30].

In general, the rats did not show behavioral changes. The three groups of rats presented a normal healing at 28 days in the wound site as shown in Figure 7. The wound healing days are similar to those reported by Nascimento et al. [18], where they, in average, were 33 days using a chitosan gel with silver sulfadiazine. It can be observed that rats treated with chitosan gel with AuNPs (Au02Ch3.5) showed the presence of a scar in the wound site (Figure 7(b)). In the histological analysis the same group of rats showed a moderate infiltration of leukocytes compared with the light infiltration in the other two groups of rats. The previous result could suggest that gold nanoparticles produce more swelling leading to a more delayed wound healing, possibly due to a toxic effect produced by the contact of the gold nanoparticles with the skin cells, something that is in accordance with previous reports [31, 32], where silver and gold nanoparticles were compared in cytotoxicity and biocompatibility essays.

\section{Conclusions}

Chitosan gels with silver and gold nanoparticles were prepared with different amounts of the reagents in order to evaluate the resulting characteristics given by the change in 

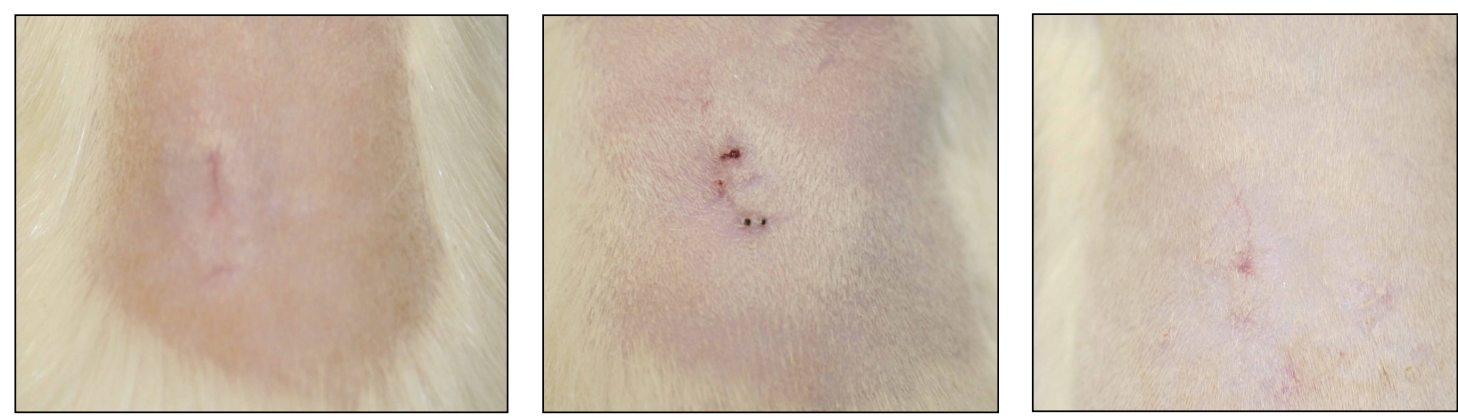

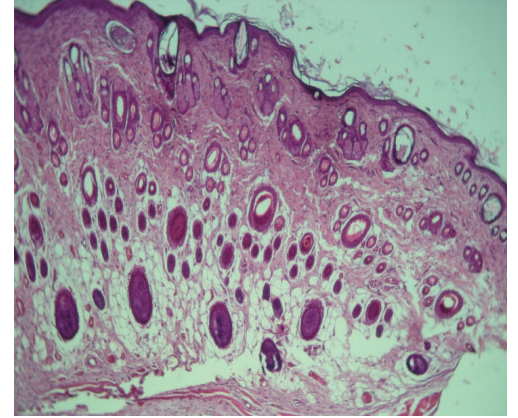

(a)

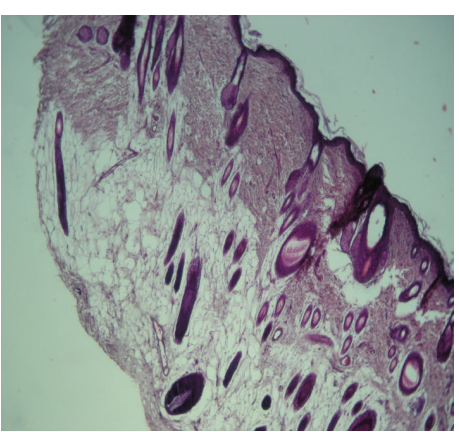

(b)

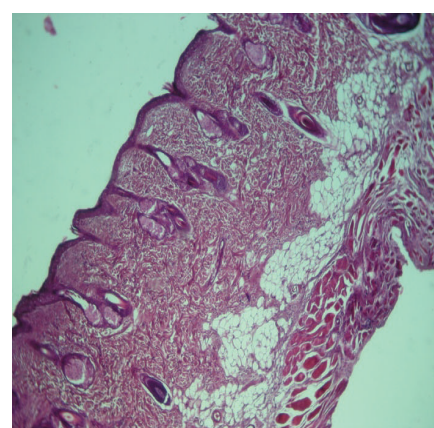

(c)

FIGURE 7: The images represent the healed wounds performed in the dorsum of the rats after 28 days with their respective histological analysis observed at $1000 \mathrm{X}$. (a) $3.5 \%$ chitosan gel with $0.1 \%$ silver nanoparticles. (b) $3.5 \%$ chitosan gel with $0.02 \%$ gold nanoparticles. (c) $3.5 \%$ chitosan gel without nanoparticles and $4 \%$ acetic acid concentration.

concentrations. The gels presented a better thermal stability due to the combination with the metal nanoparticles. When the chitosan concentration decreased the consistency of the gels was better and so their manipulation. In the ESEM images the formation of cubes and dendrites was present in the case of AgNPs gels. In the antimicrobial test the best results were obtained with the reference strains; meanwhile the smaller inhibition zones were obtained with the clinical isolates of $S$. mutans due to the higher membrane resistance of this bacterium and the fact that the samples were obtained from human dental plaque and so were exposed to a wide variety of antimicrobials; the inhibition zones obtained were very similar between $\mathrm{Ag}$ and Au although the Au concentration was smaller. The biocompatibility test showed that even when the three groups of rats presented wound healing, in the case of the chitosan gel with AuNPs, the process was delayed. These gels could represent a possible infection control resource; however more information is needed.

\section{Conflict of Interests}

The authors declare that there is no conflict of interests regarding the publication of this paper.

\section{Acknowledgments}

This work was partially supported by Consejo Nacional de Ciencia y Tecnología (CONACYT Grant CB-169020), Programa de Mejoramiento del Profesorado (PROMEP), and Fondo de Apoyo a la Investigación (FAI) of Universidad Autónoma de San Luis Potosí (UASLP). C. Sámano-Valencia would like to thank CONACYT for its support with the Scholarship no. 297778.

\section{References}

[1] I. N. Okeke, A. Lamikanra, and R. Edelman, "Socioeconomic and behavioral factors leading to acquired bacterial resistance to antibiotics in developing countries," Emerging Infectious Diseases, vol. 5, no. 1, pp. 18-27, 1999.

[2] J. R. Morones, J. L. Elechiguerra, A. Camacho et al., "The bactericidal effect of silver nanoparticles," Nanotechnology, vol. 16, no. 10, pp. 2346-2353, 2005.

[3] R. A. M. Exterkate, W. Crielaard, and J. M. Ten Cate, "Different response to amine fluoride by Streptococcus mutans and polymicrobial biofilms in a novel high-throughput active attachment model," Caries Research, vol. 44, no. 4, pp. 372-379, 2010.

[4] R. P. Allaker, "The use of nanoparticles to control oral biofilm formation," Journal of Dental Research, vol. 89, pp. 1175-1186, 2010.

[5] L. F. Espinosa-Cristóbal, G. A. Martínez-Castañón, R. E. Martínez-Martínez, J. P. Loyola-Rodríguez, J. F. Reyes-Macías, and F. Ruiz, "Antibacterial effect of silver nanoparticles against Streptococcus mutans," Materials Letters, vol. 63, no. 29, pp. 2603-2606, 2009.

[6] W. J. Loesche, "Role of Streptococcus mutans in human dental decay," Microbiological Reviews, vol. 50, no. 4, pp. 353-380, 1986.

[7] L. Zhang, F. X. Gu, J. M. Chan, A. Z. Wang, R. S. Langer, and O. C. Farokhzad, "Nanoparticles in medicine: therapeutic 
applications and developments," Clinical Pharmacology and Therapeutics, vol. 83, no. 5, pp. 761-769, 2008.

[8] B. Hong, J. Kai, Y. Ren et al., "Highly sensitive rapid, reliable, and automatic cardiovascular disease diagnosis with nanoparticle fluorescence enhancer and MEMS," Advances in Experimental Medicine and Biology, vol. 614, pp. 265-273, 2008.

[9] Q. Chaudhry, M. Scotter, J. Blackburn et al., "Applications and implications of nanotechnologies for the food sector," Food Additives and Contaminants A: Chemistry, Analysis, Control, Exposure and Risk Assessment, vol. 25, no. 3, pp. 241-258, 2008.

[10] J. E. Paddle-Ledinek, Z. Nasa, and H. J. Cleland, "Effect of different wound dressings on cell viability and proliferation," Plastic \& Reconstructive Surgery, vol. 117, no. 7S, pp. 110S-118S, 2006.

[11] E. Ülkür, O. Oncul, H. Karagoz, E. Yeniz, and B. Çeliköz, "Comparison of silver-coated dressing (Acticoat), chlorhexidine acetate $0.5 \%$ (Bactigrass), and fusidic acid $2 \%$ (Fucidin) for topical antibacterial effect in methicillin-resistant Staphylococcicontaminated, full-skin thickness rat burn wounds," Burns, vol. 31, no. 7, pp. 874-877, 2005.

[12] D. G. Maki, "In vitro studies of a novel antimicrobial lueractivated needleless connector for prevention of catheterrelated bloodstream infection," Clinical Infectious Diseases, vol. 50, no. 12, pp. 1580-1587, 2010.

[13] S. A. Moreno-Álvarez, G. A. Martinez-Castanon, N. NiñoMartínez et al., "Preparation and bactericide activity of gallic acid stabilized gold nanoparticles," Journal of Nanoparticle Research, vol. 12, no. 8, pp. 2741-2746, 2010.

[14] G. Gosheger, J. Hardes, H. Ahrens et al., "Silver-coated megaendoprostheses in a rabbit model - an analysis of the infection rate and toxicological side effects," Biomaterials, vol. 25, no. 24, pp. 5547-5556, 2004.

[15] J. Jain, S. Arora, J. M. Rajwade, P. Omray, S. Khandelwal, and K. M. Paknikar, "Silver nanoparticles in therapeutics: development of an antimicrobial gel formulation for topical use," Molecular Pharmaceutics, vol. 6, no. 5, pp. 1388-1401, 2009.

[16] V. K. Sharma, R. A. Yngard, and Y. Lin, "Silver nanoparticles: green synthesis and their antimicrobial activities," Advances in Colloid and Interface Science, vol. 145, no. 1-2, pp. 83-96, 2009.

[17] P. Sanpui, A. Murugadoss, P. V. D. Prasad, S. S. Ghosh, and A. Chattopadhyay, "The antibacterial properties of a novel chitosan-Ag-nanoparticle composite," International Journal of Food Microbiology, vol. 124, no. 2, pp. 142-146, 2008.

[18] E. G. do Nascimento, T. B. M. Sampaio, A. C. Medeiros, and E. P. de Azevedo, "Evaluation of chitosan gel with $1 \%$ silver sulfadiazine as an alternative for burn wound treatment in rats," Acta Cirúrgica Brasileira, vol. 24, no. 6, pp. 460-465, 2009.

[19] Y. Wang, M. Chen, X. Li, Y. Huang, and W. Liang, "A hybrid thermo-sensitive chitosan gel for sustained release of Meloxicam," Journal of Biomaterials Science, Polymer Edition, vol. 19, no. 9, pp. 1239-1247, 2008.

[20] T. Vamshi Krishna and Y. Madhusudan Rao, "Formulation and evaluation nasal insulin gel," International Journal of Pharmacy and Pharmaceutical Sciences, vol. 2, no. 3, pp. 161-164, 2010.

[21] W. Wang, S. Itoh, T. Aizawa et al., "Development of an injectable chitosan/marine collagen composite gel," Biomedical Materials, vol. 5, no. 6, Article ID 065009, 2010.

[22] G. A. Martinez-Castanon, N. Niño-Martínez, F. MartínezGutierrez, J. R. Martínez-Mendoza, and F. Ruiz, "Synthesis and antibacterial activity of silver nanoparticles with different sizes," Journal of Nanoparticle Research, vol. 10, no. 8, pp. 1343-1348, 2008.
[23] C. Sámano-Valencia, G. A. Martínez-Castañón, R. E. MartínezMartínez et al., "Bactericide efficiency of a combination of chitosan gel with silver nanoparticles," Materials Letters, vol. 106, pp. 413-416, 2013.

[24] R. Hernández, V. Zamora-Mora, M. Sibaja-Ballestero, J. VegaBaudrit, D. López, and C. Mijangos, "Influence of iron oxide nanoparticles on the rheological properties of hybrid chitosan ferrogels," Journal of Colloid and Interface Science, vol. 339, no. 1, pp. 53-59, 2009.

[25] M. N. Khalid, F. Agnely, N. Yagoubi, J. L. Grossiord, and G. Couarraze, "Water state characterization, swelling behavior, thermal and mechanical properties of chitosan based networks," European Journal of Pharmaceutical Sciences, vol. 15, no. 5, pp. 425-432, 2002.

[26] D. Hritcu, M. I. Popa, N. Popa, V. Badescu, and V. Balan, "Preparation and characterization of magnetic chitosan nanospheres," Turkish Journal of Chemistry, vol. 33, no. 6, pp. 785-796, 2009.

[27] C. G. T. Neto, J. A. Giacometti, A. E. Job, F. C. Ferreira, J. L. C. Fonseca, and M. R. Pereira, "Thermal analysis of chitosan based networks," Carbohydrate Polymers, vol. 62, no. 2, pp. 97 103, 2005.

[28] Y.-K. Twu, Y.-W. Chen, and C.-M. Shih, "Preparation of silver nanoparticles using chitosan suspensions," Powder Technology, vol. 185, no. 3, pp. 251-257, 2008.

[29] S.-H. Hsu, Y.-B. Chang, C.-L. Tsai, K.-Y. Fu, S.-H. Wang, and H.-J. Tseng, "Characterization and biocompatibility of chitosan nanocomposites," Colloids and Surfaces B: Biointerfaces, vol. 85, no. 2, pp. 198-206, 2011.

[30] K. A. Juby, C. Dwivedi, M. Kumar, S. Kota, H. S. Misra, and P. N. Bajaj, "Silver nanoparticle-loaded PVA/gum acacia hydrogel: synthesis, characterization and antibacterial study," Carbohydrate Polymers, vol. 89, no. 3, pp. 906-913, 2012.

[31] A. Travan, C. Pelillo, I. Donati et al., "Non-cytotoxic silver nanoparticle-polysaccharide nanocomposites with antimicrobial activity," Biomacromolecules, vol. 10, no. 6, pp. 1429-1435, 2009.

[32] E. Marsich, A. Travan, I. Donati et al., "Biological response of hydrogels embedding gold nanoparticles," Colloids and Surfaces B: Biointerfaces, vol. 83, no. 2, pp. 331-339, 2011. 

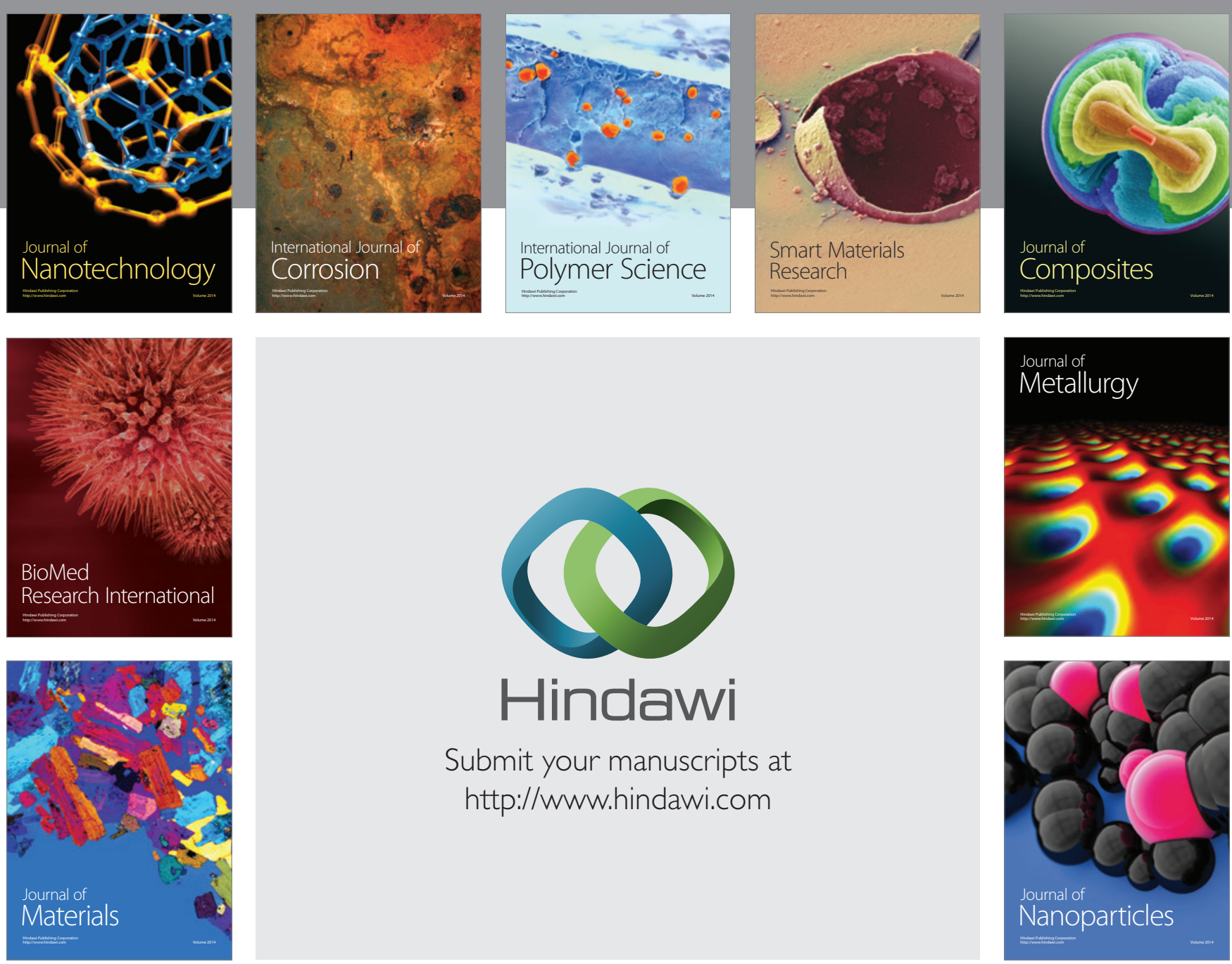

Submit your manuscripts at http://www.hindawi.com
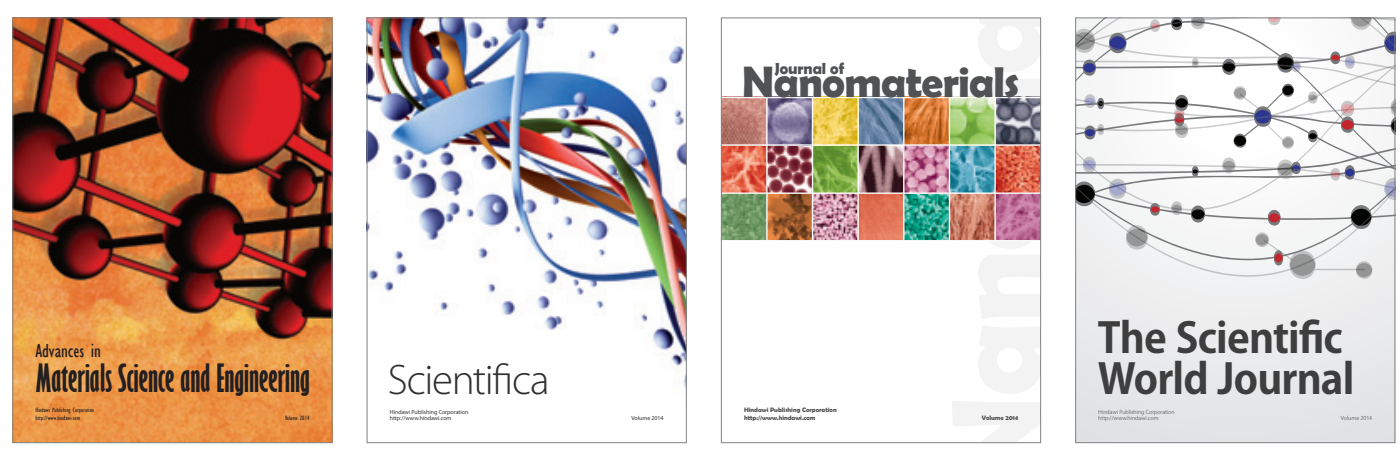

\section{The Scientific World Journal}
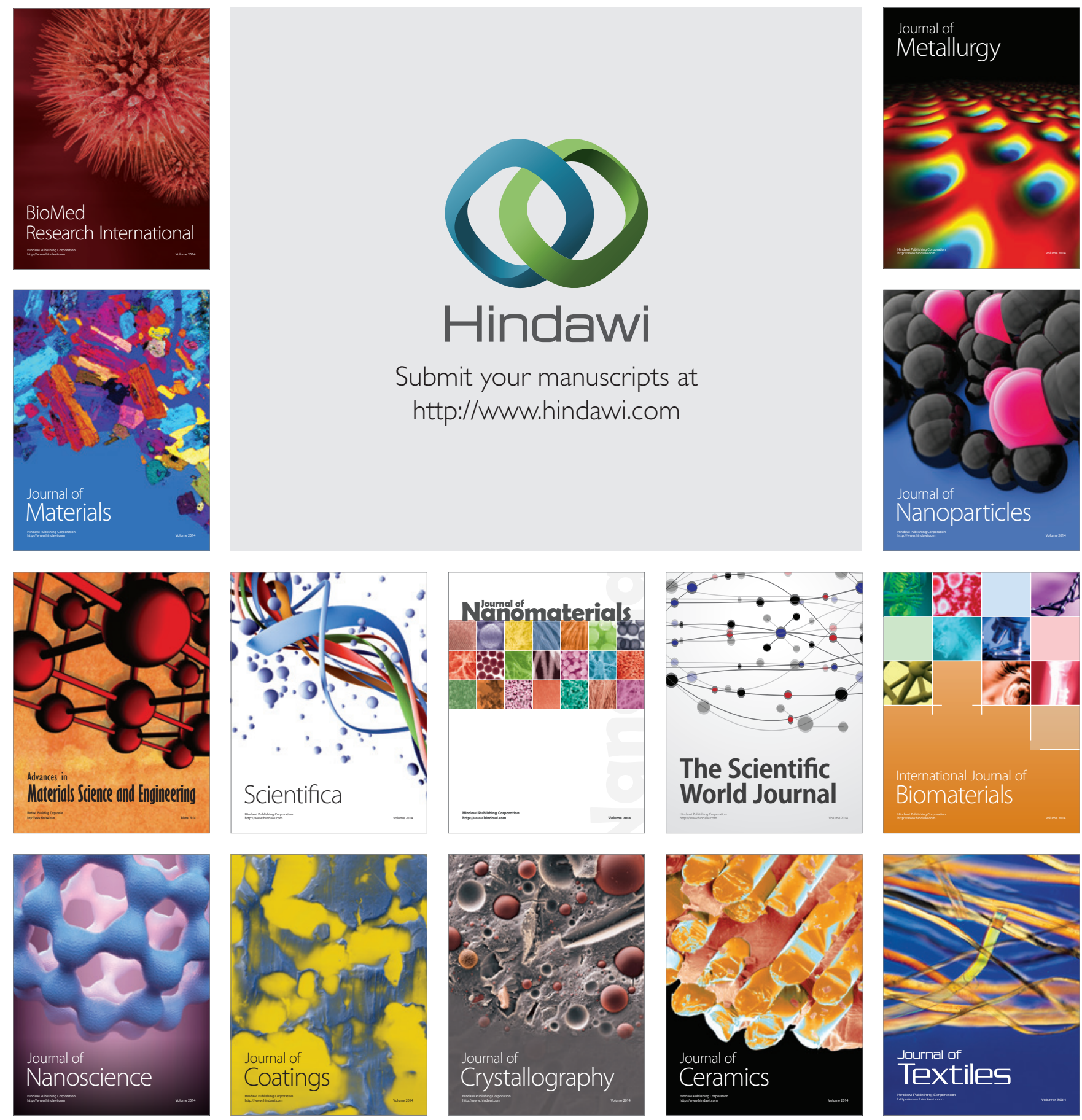